This is the peer reviewed version of the following article: Pink, S. and Morgan, J. (2013), Short-Term Ethnography: Intense Routes to Knowing. Symbolic Interaction, 36: 351-361, which has been published in final form at https://doi.org/10.1002/symb.66. This article may be used for non-commercial purposes in accordance With Wiley Terms and Conditions for self-archiving. 


\section{SHORT-TERM ETHNOGRAPHY: INTENSE ROUTES TO KNOWING}

\section{Sarah Pink (RMIT University and Loughborough University) and Jennifer Morgan (Loughborough University)}

\section{Introduction}

In this article we explore how short-term theoretically informed ethnography is emerging as an approach to doing research that is contemporary in both its subject matter and in its use for applied research projects designed to lead to informed interventions in the world. This is not to say that short-term ethnography itself is a new phenomenon. However, when set in a contemporary context, short-term ethnography can be interpreted in relation to a particular set of research practices and types of significance. These, we will outline in terms of what we call the qualities of short-term ethnography.

Ethnography is an established approach to doing research, which the anthropologist Tim Ingold suggests, has as its objective 'to describe the lives of people other than ourselves, with an accuracy and sensitivity honed by detailed observation and prolonged first-hand experience' (2008a: 69). Ingold goes on to argue that ethnography however is not anthropology, which he sees as a different scholarly endeavor. Indeed ethnography tends to become shaped by the discipline it is being engaged through, and this in itself makes it rather slippery to define. In terms of its length, there is a tendency, particularly in anthropology to assume that ethnography is a necessarily long-term research process, where conventionally $\mathrm{PhD}$ students spend (at least) a whole calendar year doing 'fieldwork'. 
In practice however, in other contexts, including design research and applied uses of ethnography in corporate and health research contexts, ethnography is not always characterized through long-term engagement with other people's lives. Rather it involves intensive excursions into their lives, which use more interventional as well as observational methods to create contexts through which to delve into questions that will reveal what matters to those people in the context of what the researcher is seeking to find out. For example, in the field of public health research and planning, the influential rapid anthropological methodologies known as Rapid Assessment Procedures (Scrimshaw and Hurtado 1987) or Rapid Ethnographic Assessment (Bentley et al. 1988) were developed in response to perceived inadequacies of traditional anthropological research to contribute to programmes of disease management in a timely and resource efficient manner (Harris, Jerome and Fawcett 1997: 375). These rapid methodologies are also characterized by research activities being undertaken in a shorter time frame (typically weeks and months rather than years), the multi-disciplinary nature of teams, the use of mixed methods of data collection, and an emphasis on findings leading to applied interventions. Yet as we elaborate below there is a crucial difference between such approaches and short-term ethnography as discussed here. Rapid assessment approaches tend to demand, as Manderson and Aaby (1992: 46) describe, 'a separation of anthropological theory and method, and a truncation of techniques and skills in applied contexts'. The short-term ethnography approach we outline here advances this practice precisely by showing how its delivery benefits from a sharply focused dialogue between research and theory.

In the practice of short term ethnography it is not so much the use of new techniques and interventional technologies to get closer to other people's experiences 
that is engaged to make short term ethnographies intense/intensive and ethnographically rich. Rather it is the use of techniques and technologies in different ways. Another influential example has been what David Millen (2000) calls 'Rapid Ethnography', an approach that he developed in a HCI (Human Computer Interaction) context. Millen describes this as allowing 'an HCI team to better understand users, the user environments, the interaction between the two -- in a shortened timeframe'. To achieve this a number of measures are taken: 'more focused observation, better selection of informants, multi-person research teams with greater informant interaction and better data analysis tools' (Millen 2000: 285). It has also been important for advocates of short-term ethnography to defend it against potential criticisms. For example the sociologist Hubert Knoblauch redefines short-term ethnographies as 'focused ethnographies' in response to what he notes is 'The standard argument against this short-ranged character is that these kinds of ethnographies are "superficial"' (Knoblauch 2005: [16]). He goes on to argue for a concept of 'focused ethnography' for which he proposes 'The short time period covered is compensated for by another type of intensity: focused ethnographies are typically data intensive' (Knoblauch 2005: [16]). To create this intensity of data such approaches use video observations of activity, which are closely analysed, thus creating a depth of data and immersion, which is brought forth at the analytical stage of the ethnography.

Therefore in these areas of design and health research and in Sociological micro-ethnography we are dealing with a rather different type of research scenario to that expected in for instance conventional anthropological ethnography. The difference is shown well if we consider how Hughes et al have used the term 'quick and dirty' to describe a type of short term ethnography which they tell us 'not only 
seeks relevant information as quickly as possible but accepts at the outset the impossibility of gathering a complete and detailed understanding of the setting at hand' (1995: 61). We would distance ourselves from this interpretation of short term ethnography as 'quick and dirty' versions of the longer-term traditional ethnography. Instead they entail using different methodological, practical and analytical entry points into the lives of others.

We will therefore suggest treating short term ethnography rather differently, and in such a way that it both maintains the first hand involvement of the ethnographer as a core element in the way that she or he comes to know about other people's lives and experiences, takes a more deliberate and interventional approach to that of long term participant observation and is also theoretically engaged. Such shortterm ethnography is suited to a series of theoretical, methodological and empirical interests, which converge in the contemporary context in which we are working. These include theoretical turns towards practice, practical activity (what people are actually doing as the move through the world) and the nonrepresentational (the unspoken, unsaid, not seen, but sensory, tacit and know elements of everyday life). Such approaches are also supported by the ubiquity of digital media in both the everyday environments we research and in our research practices. Both a close and intentional focus on the detail of everyday practices, and the ability to probe and intervene in such ways that the 'invisible' and unspoken elements of everyday life emerge as research knowledge are possible in long-term research. However, our point is that if this is what we are seeking to understand, it is useful to go beyond observation to create short term research engagements that benefit from the production of forms of intensity, empathy and an ongoing ethnographic-analyticaltheoretical dialogue. Indeed to achieve this we often need to intervene in peoples lives 
in new ways, that are intensive, potentially intrusive and involve asking what they might think are irrelevant questions. None of which is sustainable over long periods of time.

In what follows we first outline an approach to short term ethnography that frames the research context theoretically as a type of 'ethnographic place' (Pink 2009) which brings to the fore the ways in which it can develop as part of project ecologies. We then discuss a series of qualities, which we associate with short-term ethnography. While we would not claim that these are necessarily exclusive to short term ethnography, together they characterize its practice in such a way as to suggest how they might be played out in future work. We illustrate, on the basis of our own experiences of a recent ethnographic fieldwork stay in a Health Care Trust in the UK during six weeks, how these qualities have been engaged through the techniques and practice of ethnography. In doing so, we outline ways of knowing and the status of the types of knowledge such research techniques might produce. We also, where relevant compare these ways of learning and knowing with our experiences of doing long-term ethnography.

\section{The Ethnographic Place}

Pink has developed the concept of the 'ethnographic place' (2009) as a way in which to explain how a range of different types, qualities and temporalities of things and persons come together as part of the process of the making of ethnographic knowledge or ways of knowing. Drawing on the work of geographer Doreen Massey and anthropologist Tim Ingold she understands place as ‘open' (Massey 2005) or 'unbounded' (Ingold 2008b), and as standing for a collection or configuration of things of which locality can be part, but yet go beyond locality. The ethnographic 
place also extends beyond the context in which the ethnography is done, to the contexts in which it is analysed and disseminated. Therefore it encompasses the different temporalities of these processes, but at the same time enables us to accommodate the temporalities where these overlap. In the context of the project we discuss here, this is particularly pertinent to understanding the research process. The fieldwork undertaken by Jennie Morgan (JM) led on from a research project undertaken at the same site by two Loughborough University MSc students whose previous field encounters and findings became entangled in our access negotiations, in framing our research questions and remained embedded in JMs fieldwork encounters. The digital layers through which the fieldwork was undertaken as we show below created an interweaving of fieldwork and analysis through ongoing discussion between JM, Sarah Pink (SP) and our colleague Andrew Dainty. Moreover, dissemination entered into this temporality of place as this article was being written while the fieldwork was ongoing. Ethnographic places are therefore not fieldwork localities, but rather they are the entanglements through which ethnographic knowing emerges.

The ethnographic places of long-term ethnography can be qualitatively different, in both our experiences of having undertaken traditional year-long $\mathrm{PhD}$ research and in SP's subsequent work. In short-term fieldwork such as that discussed here, the 'lone ethnographer' model, and the unfolding and emergent nature of ethnographic knowledge takes on a new dimension. In short-term projects that involve a number of agents and especially when ethnographers are on board for only part of the duration of the project knowledge emerges as field-materials flow between different people at different times. The sets of encounters through which ethnographic knowledge/knowing emerges, are qualitatively different, their development is rapid, 
and intense, and will grow in different ways as encountered by different people, arguments and ways of knowing long beyond the life of the fieldwork itself.

In some cases the length of time spent in a particular fieldwork locality makes the ethnography short-term, in others the multisited fieldwork means the 'immersion' of the ethnographer is for only a short period. The example we discuss here is of a six-week immersion. Pink's ethnographic work on the home (Pink 2004, 2012a, Pink and Leder Mackley 2012) provides a contrasting model whereby visits to participants' homes range from a few hours to several repeat visits. The concept of the ethnographic place enables us to picture these processes through a wider vision: even when the actual encounter is short and very intense our ethnographic engagement with the fieldwork context, can be much more, through online involvement, and reengagement though video, potentially lasting for years.

\section{The qualities of short-term ethnography}

We now consider a series of qualities of short-term ethnography that have emerged from our work. We do not intend to be definitive in stating these, but rather to initiate a debate capable of reflecting on the types of ethnographic knowing these qualities generate, and the implications of these.

\section{The intensity of the research encounter}

Conventional long-term ethnography tends to be characterized by a lot of 'hanging around', waiting for things to happen. Ethnographers often suffer concerns that they will never be 'accepted' enough to undertake their fieldwork (although they usually are). In our short-term focus, instead, the ethnographer seeks to implicate her or himself at the centre of the action, right from the start, and engages participants in the 
project with this intention clearly stated. For example in her research into everyday life in the home SP has invited participants to perform everyday tasks that involve quite intense activity. For instance, cleaning their bathrooms, in which for example, a participant took on board the normally unspoken about and tacitly known task of scrubbing off limescale (see Pink 2012b). Another kind of performance was invited by JM in the healthcare context. JM asked professionals - after observations of clinical and therapy work, and in follow-up interviews - to demonstrate and describe to her the use of various equipment, tools, and other material features of the workplace (e.g., gloves, cell-phones, personal alarms). This did not involve the same physical intensity as performances in the home, but had a similar goal of using this exercise to implicate JM in the center of activity in a way that less implicated observation would not generate. By being shown how to use disinfectant hand-gels, and listening to workers accounts of the sensory and bodily experience of its use, JM could 'see' an everyday, ongoing, and common-sense practice through which workers 'do safety'. Moreover, by routinely using hand-gels herself during observations of community healthcare visits (on encouragement from participants), she experienced how its use can create a sense of safety by not only actually cleaning hands, but managing embodied emotions or feelings of being dirty, grimy, and so on.

Through these collaborations with participants, the intensity of the research encounter becomes part of the way that we learn and empathise in short term research. In fact spending up to four or so hours with one person in a context where one is focused on trying to understand or imagine their embodied practices, sensations or emotions, asking them questions about this and reflecting on one's own affective responses, is an exhausting experience. Both of us began to feel overwhelmed by the depth and intensity of our respective research encounters. We had journeyed into what 
was important to the participants, learned about elements of their everyday home and work lives that they normally did not talk with anyone about. These were encounters with moments in other people's worlds that could feel very serious and were fundamental to how they experienced the everyday.

\section{A focus on the detail}

Long-term participant observation often involves a technique where an ethnographer becomes an 'apprentice' (see Pink 2009), learning to be a skilled practitioner in the activities participants perform, and as such seeking to understand these through their own embodied experiences. In short-term fieldwork, this is not 'lost' but is developed through different possibilities for engagements with the detail of other people's experiences. It is not only the short-term nature of our work that has made it difficult to learn to do the actual tasks that participants are engaging in, but because in the health care context, short of training as a health care professional this would not be appropriate (or ethical). This instead invites us to make correspondences between the experiences of research participants and our own (see Okely 1994). In doing so the technique of drawing from past experiences to understand the principles of what participants are seeking to achieve offers a means of creating bridges between their and the ethnographer's experiences. The embodied residues of sensory memory form a key element of this approach. For example, in the healthcare context, JM drew on her experience of using touch in her prior work as a museum curator to make correspondences with how nurses also use their hands in skilled and sensory ways. Although carried from a very different professional context, this experience enabled $\mathrm{JM}$ to recognize and ask participants to reflect on practices that were unspoken and 
would have been otherwise invisible, such as the removal of a fingertip from a pair of gloves to allow for the sensation of touch to be used when taking a blood sample.

This focus on detail is not a replacement for participant observation or embodied learning on the part of the ethnographer. However it accounts for contexts where the specialist nature of the training needed for apprenticeship methods would require a long-term commitment, and would thus, become the research topic itself. Yet when the research objective is to focus on detail as a route to addressing a wider question across different sectors rather than on embedding oneself in one - as it is in the case of our study of OSH - then a different approach is needed.

\section{The ethnographic-theoretical dialogue}

Ethnographic research evolves in dialogue with theory rather than being led or structured by theory. In long term research this dialogue might be less intense, and may indeed take place largely at the end of the fieldwork, or at certain points of review. In short term ethnography the focus is sharper, the research questions need to be responded to more firmly and data collection and analysis intertwined. Yet there is also scope for changing the question or arriving at it in a roundabout way. One way this can be achieved is by maintaining a certain intensity in the ethnographictheoretical dialogue as the research develops. This involves continually bringing theoretical questions into dialogue with the ethnography. There are ways in which the lone researcher can do this, for instance by taking time away from fieldwork, and presenting preliminary work to peers. However in the Health Care ethnography context we developed this through an actual dialogue between JM, SP and AD. SP, located in Melbourne Australia and AD located in Loughborough UK followed the process through fieldnotes, commentaries and photographs. We corresponded nearly 
every day throughout the fieldwork and at one review meeting JM presented her progress to the wider project team. Although not planned, being in different time zones built the intensity of the ethnography meaning we could work on the project at any time over the 24 hour period. This dialogue shaped the types of questions that were asked, what activities were followed, the spaces and relationships that the researcher attempted to position herself within, and the kinds of collaborative encounters created or sought out.

For example, a crucial moment that came to fundamentally guide the research process occurred through an intense email dialogue between JM and SP during the first days on site. In attempting to begin observing the everyday work of healthcare professionals, and explore the research topic of OSH-knowledge 'flows', JM was frustrated that she could not 'see' OSH-knowledge in ways she had anticipated. She wrote to SP:

I don't in any way wish to suggest it is not present (indeed, this morning I sat in on a training session on infection control, I have encountered various pieces of policy, etc), BUT ... there isn't the immediately obvious kinds of materials such as signage etc which would be entry points of knowledge flowing into organisations. I am grappling with the idea of 'what' to follow...

In reply, SP emailed:

The way that OSH knowledge is not that conspicuous in terms of paperwork and signage is perhaps not that surprising, and I am wondering if when it is present if staff really even notice it as they go about everyday work ... keep in mind that staff will probably not explicitly be discussing OSH - they are more 
likely to be using different categories. One way to approach this is to seek to find out what these categories are, and/or invent one of your own through which to talk about OSH. So, I would suggest watching out for instances when people express in non OSH terms things relating to not hurting themselves, taking care etc, and keep in mind that these might not be verbal but could be embodied actions.

Guided by the analytic framework of the research (Pink et al submittted), approaches to the idea of knowing and learning as embodied, sensory and emplaced (Fors et al 2012), which are also relevant to organization studies (Pink et al 2013), SP encouraged JM to consider what might be implicit to the work of healthcare professionals at this site that minimizes risk. Inspired by debates in media studies, SP asked questions relating to the ubiquity of digital media in everyday life wondering how 'media presence' by beyond its actual use and standby-modes (which are part of everyday life media use in the home (Pink and Leder Mackely submitted) formed part of OSH. The idea of seeking to understand what was 'already there' in the background but nevertheless creating a sense that things were in place, led us to what we have conceptualised as 'quiet safety'. Through this theme, JM was able to focus how OSH was indirectly invested in everyday, ongoing, and taken-for-granted practices - including the use of mobile phones, hand-gels (see above) and the wearing of uniforms - that enable workers to create or make a sense of safety. The intensity of this dialogue was key to responding to our research objectives in a way that intertwined theoretical-analysis and empirical observations, and facilitated a continuous engagement with the research process. 
We have already noted the use of video in short term ethnography and indeed the use of visual media and images (and material objects as probes) in disciplines that typically use short term ethnography is common. In SP's work visual methods and media have formed an important element in short term ethnography, not least in her multisited ethnographic work in homes where it would be too intrusive to develop long term encounters. In this approach however we are not simply seeking to produce rich visual data for an intensive analysis, but instead see re-viewing the materials as an ongoing form of re-engagement with the materials and the context. As Pink discusses elsewhere this means in fact coming to understand it anew each time. Indeed in the example we focus on here, the relationship between the production of visual research materials and the fieldwork context can be complex. For example, we were interested in video recording the use of hand gels. It would have been impossible to do this in situ during health care work, although sometimes photographed when in the worker's car. It was nevertheless important because we wished to understand the meaning of gels for safety and the tacit ways of knowing that they had been applied correctly, using video and photography would help us to invite participants to reflect on their tacit ways of knowing and feeling safe. Therefore these practices were video recorded and discussed with participants again when, re-performed later in follow-up interviews.

While there is no space here to discuss visual ethics in short term ethnography we would also note that an ongoing process of informed consent is part of this process, which is particularly important for building trust in participants in the use of images. This ongoing consent process moreover establishing channels of communication beyond the fieldwork setting with participants from the outset and 
continues them after it, again, expanding the ethnographic place by enabling participants to enter into our post-fieldwork temporality in decisive ways.

\section{Conclusion}

In this article we have described three types of intensity: of the research encounters themselves; of the ethnographic-theoretical dialogue; and of the post-fieldwork engagements with materials. All of these play key roles in the way the ethnographic places of short-term multi-researcher ethnography might be constituted.

There is of course a relationship between the length of fieldwork and project deadlines, available resources and access parameters, which bears on such projects. These might well be defining moments in terms of when the decision to undertake short-term ethnography is take. Indeed we do not wish to argue for short-term ethnography as a 'better' replacement for long-term ethnographic immersion. However rather than conceptualizing shorter time-scales as as 'limitations' it is more fruitful to see them as part of wider project ecologies whereby ethnography takes on particular temporal and spatial characteristics as well as specific qualities. Our argument is that short-term ethnography is not only (or even dominantly) characterized by its temporal nature. It is not simply an inferior way to do ethnographic research that is imposed by the time constraints and demands of applied agendas, funding and pressure to publish. It is rather a route to producing alternative ways of knowing about and with people and the environments of which they are part. While short-term ethnography might be inspired by long-term ethnographic fieldwork methods to some extent, it is not simply a version or variant of them. Indeed as developed in the projects discussed in this article, the key inspiration for the techniques we have used in short-term ethnographic projects has been in visual 
anthropology and ethnographic filmmaking methods (see Pink 2007), rather than from conventional approaches to fieldwork. Indeed it is from within short-term ethnography projects that we have generated innovative research techniques.

Yet, short-term ethnography as we have developed it is not disassociated from its academic roots in anthropology. It draws from contemporary renderings of anthropological ethnography, originating in the late twentieth century reflexive turn of the 'writing culture' debate (Clifford and Marcus 1986) and its legacy (Hockey et al 1997) the idea anthropological ethnography involves doing research with rather than about participants (Ingold 2008a). Thus, short-term ethnography as we define it differs from its uses in other disciplines in that it shaped by, and contributes to, distinctly anthropological ways of understanding and being in (and with) the world.

The account we have given here is intended as a starting point for thinking about short-term ethnography, and not as a prescriptive 'how to' model. In this wider sense our aims have been two-fold: to create a basis from which to begin to conceive short term ethnography methodologies, which will always be project specific; and to inspire further dialogue, insights and discussion of this field of ethnographic practice.

\section{Acknowledgements}

The fieldwork discussed in this article is based on ethnographic research undertaken by Jennifer Morgan in collaboration with Sarah Pink and Andrew Dainty. Our first thanks go to the people who gave up time during their busy working lives to participate in this project, and help arrange our research placement, since without their collaboration this article would not have been possible. The research is being conducted as part of a project entitled 'Management of OSH in Networked Systems of Production or Service Delivery: Comparisons between Healthcare, Construction and 
Logistics', funded by the Institution of Occupational Safety and Health (IOSH) as part of their Health and Safety in a Changing World programme. We are grateful to IOSH, and in particular to Robert Dingwall and Jane White for their support of our work. The project is based at Loughborough University, UK, where we are grateful for the collaboration and support of our colleagues and co-researchers, in particular in relation to this article to Andrew Dainty, Patrick Waterson and Alistair Gibb for their support in developing the research and writing for this article.

\section{References}

Bentley, M. E., G. H. Pelto, W. L. Straus, D. A. Schumann, C. Adegbola, E. De La Pena, G. A. Oni, K. H. Brown and S. L. Huffman (1988) 'Rapid Ethnographic Assessment: Applications in a Diarrhea Management Program’ Social Science and Medicine, 27(1): 107-116.

Clifford, J. and Marcus, G. (1986) Writing Culture: the Poetics and Politics of Ethnography. Berkeley: University of California Press.

Fors, V., A. Backstrom and S. Pink (2012) 'Multisensory emplaced learning: resituating situated learning in a moving world' Mind, Culture, and Activity: An International Journal, published on-line first at http://www.tandfonline.com/doi/abs/10.1080/10749039.2012.719991

Harris, K. J., N. W. Jerome and S. B. Fawcett (1997) 'Rapid Assessment Procedures: a Review and a Critique' Human Organization, 56(3): 375-378.

Hughes, J., V. King, T. Rodden, and H. Andersen (1995) 'The role of ethnography in interactive systems design' interactions 2(2): 56-65 
Ingold, T. (2008b) ‘Anthropology is not Ethnography’ Proceedings of the British Academy, volume 154.

Ingold, T. (2008b) 'Bindings against boundaries: entanglements of life in an open world' in Environment and Planning A, 40: 1796-1810.

James, A., Hockey, J. and Dawson, A. (1997) After Writing Culture: Epistemology and Praxis in Contemporary Anthropology. London, Routledge.

Knoblauch, H. (2005) 'Focused Ethnography'. Forum Qualitative Sozialforschung / Forum: Qualitative Social Research, North America, 6, sep. 2005. Available at: $<$ http://www.qualitative-research.net/index.php/fqs/article/view/20 $>$. Date accessed: 24 Jan. 2013.

Manderson, L. and P. Aaby (1992) 'Can Rapid Anthropological Procedures be Applied to Tropical Diseases?', Health Policy and Planning, 7(1): 46-55.

Massey, D. (2005) For Space, London: Sage

Millen, D. R. (2000) 'Rapid Ethnography: Time Deepening Strategies for HCI Field Research'. In Proceedings of the 3rd Conference on Designing Interactive Systems: Processes, Practices, Methods, and Techniques, 280-286. DIS '00. New York, NY, USA: ACM. doi:10.1145/347642.347763.

Okely, J. (1994) 'Vicarious and sensory knowledge of chronology and change: ageing in rural France', in K. Hastrup and P. Hervik (eds), Social Experience and Anthropological Knowledge. London: Routledge.

Pink, S. (2004) Home Truths: gender, domestic objects and everyday life, Oxford: Berg

Pink, S. (2009) Doing Sensory Ethnography, London: Sage

Pink, S. (2012a) Situating Everyday Life: practices and places, London: Sage 
Pink, S. (2012b) 'Domestic time in the sensory home: on knowing in practice in the bathroom' in E. Keightly (ed) Time, Media and Modernity, Basingstoke: Palgrave, pp184-200.

Pink, S. and K. Leder Mackley 'Saturated and Situated: rethinking media in everyday life' submitted to Media, Culture and Society

Pink, S. and K. Leder Mackley (2012) 'Video as a Route to Sensing Invisible Energy' Sociological Research Online, February 2012, on line at http://www.socresonline.org.uk/17/1/3.html

Pink, S., A, Dainty and D. Tutt (eds) (2013) Ethnographic Research in the Construction Industry, London: Taylor and Francis

Pink, S., P. Waterson, A. Dainty, A. Cheyne, R. Haslam, A. Gibb, J. Morgan, R, Hartley, A. Finneran, P. Bust (submitted) ‘Knowledge, Practice and Flow: towards an interdisciplinary perspective on occupational safety and health knowledge' submitted to Safety Science.

Scrimshaw, S. C. M., and E. Hurtado (1987) Rapid Assessment Procedures for Nutrition and Primary Health Care: Anthropological Approaches to Improving Programme Effectiveness, Tokyo: The United Nations University 